\title{
Mechanism of leaf-cutting ant colony suppression by fipronil used in attractive toxic baits
}

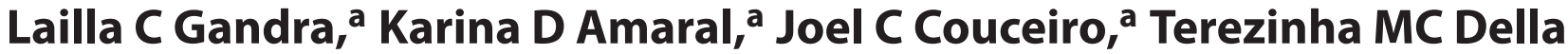 \\ Lucia $^{b}$ and Raul NC Guedes ${ }^{a^{*}}$
}

\begin{abstract}
BACKGROUND: Attractive toxic baits are the prevailing method for managing leaf-cutting ants in the eucalypt forests planted for the production of pulp, paper, timber and charcoal. For successful use in these baits, the insecticidal compounds need to circumvent the typical defences of the eusocial leaf-cutting ants. The challenge is to have an insecticide in the bait that will not directly harm and/or compromise foraging workers, but that will eventually suppress the colony. These underlying mechanisms are poorly known, and here the potential mechanism of fipronil activity in toxic baits for leaf-cutting ants was assessed using colonies of the representative Neotropical Acromyrmex subterraneus subterraneus (Forel, 1893).
\end{abstract}

RESULTS: Although forager activity was not directly impaired by fipronil, the insecticide affected forager nestmate interactions (auto- and allogrooming) and waste removal and, more importantly, greatly affected the minor workers, impairing their activities of fungus garden cultivation and progeny handling. The fast decay of the fungus garden compromised the sustainability of the colonies, ultimately leading to their demise within 8 days.

CONCLUSION: The behavioural effects of sublethal insecticide exposure towards minor workers are the main determinants of insecticide activity as ant baits and should be targeted in developing such compounds.

(c) 2016 Society of Chemical Industry

Supporting information may be found in the online version of this article.

Keywords: colony suppression; ant control; leaf-cutting ant management; insecticide activity; behavioural activity; insecticide-induced impairment

\section{INTRODUCTION}

Leaf-cutting ants have been broadly recognised as important pest species in Neotropical America since the European colonisation of the New World. ${ }^{1-4}$ They are dominant species in natural as well as in human-altered environments (e.g. agricultural fields, pastures, forests), where they are a recognised as a threat to production, with conservative loss estimates in the range of billions of dollars. ${ }^{5,6}$ The concerns with leaf-cutting ants are particularly acute in planted forest systems with the prevailing use of Eucalyptus in wide monoculture expanses aimed at pulp, paper, wood and charcoal production. ${ }^{4,7,8}$

As truly social insects, leaf-cutting ants exhibit a number of peculiarities that include social organisation, foraging, fungus cultivation, hygiene and complex nest structure, which make their control notoriously difficult., ${ }^{4,5}$ This scenario is further aggravated by the current problems faced by forest companies, making leaf-cutting ant management even more challenging - the ever-increasing restrictive requirements imposed by forest certification initiatives and the lack of control agents and techniques to keep these pest species below economic thresholds. ${ }^{4,9-11}$

Insecticides are the prevailing tools used for controlling leaf-cutting ants throughout their range of occurrence. Although four distinct practices of insecticide application are used - powder application, fumigation, thermal fogging and toxic baiting - the use of the latter is widespread in planted forests., ${ }^{9,12-14}$ The success of a toxic bait against leaf-cutting ants is dependent on its attractant, the mass and size of the bait granules and the active ingredient used. Citrus extract and the current granule mass and size are optimised for targeting the main pest species attacking forest plantations. ${ }^{4,12,15,16}$ Regarding the insecticide, the use of organosynthetic compounds is pervasive, albeit restricted to a very limited number of compounds..$^{9,15}$

The limited number of active ingredients used in toxic baits is due to the atypical requirement for these compounds to suppress the colony but without compromising worker foraging, allowing

\footnotetext{
* Correspondence to: RNC Guedes, Departamento de Entomologia, Universidade Federal de Viçosa, Viçosa, MG 36570-000, Brazil. E-mail: guedes@ufv.br or rncguedes@gmail.com

a Departamento de Entomologia, Universidade Federal de Viçosa, Viçosa, MG, Brazil

b Departamento de Biologia Animal, Universidade Federal de Viçosa, Viçosa, MG, Brazil
} 
the baits to be harvested and brought to the nest. ${ }^{4}$ This is so because leaf-cutting ant baits are applied by distributing them near the ant trails and nest openings in quantities proportional to the nest size, and the foraging workers pick up the granules and introduce them into the colony, eventually leading to its death. ${ }^{15,16}$ Therefore, the direct mortality of foraging workers is an undesirable trait for insecticidal baits, contrasting with the standard focus of insecticide research rapidly killing an arthropod pest species. ${ }^{17}$

The organochlorine dodecachlor, the active ingredient of the Mirex ${ }^{\circledR}$ ant bait, was the insecticide of choice in the early use of toxic baits against leaf-cutting ants until its prohibition. . $^{13,15,16}$ This compound set a high standard for efficacy owing to its high persistence and low acute toxicity to foraging workers, allowing the baits to contaminate the nest, causing wholesale mortality of minor workers within 5 days. ${ }^{12,13,15}$ Fipronil and sulfluramid successfully followed the use of dodechlaclor in ant baits, but their underlying mechanisms to achieve colony suppression remain unknown. ${ }^{6,14,18}$ Very few compounds were subjected to such mechanistic studies, ${ }^{18-22}$ and none of them was commercially feasible. Thus, the understanding of such mechanisms of colony suppression in currently used insecticidal baits for leaf-cutting ants remains a knowledge gap impairing the development of alternative insecticides against leaf-cutting ants at a time when currently available compounds are facing pointed restrictions by forest certification companies. ${ }^{4,10,11}$

The aim of the present study was to improve our understanding of the mechanism of fipronil activity in achieving the suppression of leaf-cutting ant colonies when used in attractive baits. Colonies of the representative Neotropical leaf-cutting ant Acromyrmex subterraneus subterraneus (Forel, 1893) were used for the experiments performed under laboratory conditions. As colony suppression can be achieved either by directly compromising the minor workers, the fungus garden or the ant queen, we hypothesised that the former is more likely because fipronil is not reported as a fungicidal nor as a sterilant compound. ${ }^{23-27}$

\section{MATERIALS AND METHODS}

\subsection{Colony collection and laboratory establishment}

The leaf-cutting ant $A$. s. subterraneus was used in the experiments because it attacks eucalypt forests in Neotropical America., ${ }^{4,9,28}$ Ten colonies of this species were field collected in Viçosa County, state of Minas Gerais, Brazil $\left(20^{\circ} 45^{\prime} 14^{\prime \prime} \mathrm{S}, 42^{\circ} 52^{\prime} 54^{\prime \prime} \mathrm{W}\right)$, and established in the laboratory where they were maintained under controlled conditions of $25 \pm 5^{\circ} \mathrm{C}$ temperature, $75 \pm 5 \%$ relative humidity and $12 \mathrm{~h}$ scotophase, as described elsewhere. ${ }^{29}$ Each colony produced about $1 \mathrm{~L}$ of fungus and exhibited similar foraging activity; all of the colonies were monogynic, exhibiting progeny at each of the developmental stages (i.e. eggs, larvae and pupae) and an estimated worker number of 8000 . Each colony received weekly bait granules without insecticide (i.e. placebo baits) to allow conditioning of the foraging workers to accept baits and to prevent bait rejection during the experiments. The colonies were also daily provided ad libitum with a mixed assortment of freshly cut leaves, with the prevalence of leaves from the evergreen shrub Acalipha wilkesiana Müll. Arg. (Euphorbiacea).

\subsection{Bait application}

The ten colonies were split into two groups of five, and each individual colony was placed on a white plastic tray
$(30 \mathrm{~cm} \times 30 \mathrm{~cm} \times 10 \mathrm{~cm})$. A $14 \mathrm{~cm}$ mark was made on each tray, extending from its edge to the entrance of the ant nest, which was considered the total extent of the foraging arena of each colony. Each tray arena was further subdivided halfway along the $14 \mathrm{~cm}$ mark made (i.e. at a $7 \mathrm{~cm}$ distance). The bait granules were placed at the $14 \mathrm{~cm}$ mark at the edge of the tray, and the bait was considered as being harvested when carried over the $7 \mathrm{~cm}$ mark (i.e. half the extent of the foraging arena) in the direction of the nest. Either baits or placebo baits were offered only once to each colony.

The mass of bait given to each colony was based on the commercial label rate and amounted to $3 \mathrm{~g}$ for each colony for about a $1 \mathrm{~L}$ volume of fungus garden (Isca Attack Verde ${ }^{\circledR}, 0.003 \%$ fipronil; Biocarv Ind. Quím., Curitiba, PR, Brazil). The commercial baits containing fipronil were given just once to each of five colonies (i.e. replicates), while placebo baits without insecticide were delivered to the other five colonies. The baits remained available for picking up for $24 \mathrm{~h}$, after which the remaining granules were retrieved and weighed. A provision of freshly cut leaves (A. wilkesiana) started $24 \mathrm{~h}$ after bait provision, and $5 \mathrm{~g}$ of leaves was offered daily to each colony for the duration of the experiment, which lasted until eventual suppression of the fipronil-baited colonies (i.e. 8 days).

\subsection{Experimental measurements}

\subsubsection{Colony-based determinations}

The mass of bait harvest after the allocation, as well as the mass of freshly cut leaves collected daily by the foraging ants, was determined for each colony. ${ }^{30}$ Worker ant mortality (mass of dead workers) was also assessed daily by means of midden inspection, in which the disposed dead ants were retrieved and weighed on an analytical scale (AUW220D; Shimadzu, Kyoto, Japan). Individual counting of the dead ants was not possible owing to the large numbers and entanglement with one another.

\subsubsection{Worker-based determinations}

The behaviour of foraging and minor workers was recorded daily for each colony for $30 \mathrm{~min}$ for each caste between 8:00 and 10:30 a.m. using a digital camera (HDR-XR520V; Sony, Tokyo, Japan). These recordings were performed from the time of bait placement to the end of the experiment, which lasted until eventual suppression of the fipronil-baited colonies (i.e. 8 days). The number of waste removal activities transferring waste (e.g. dead ants, fungus fragments, etc.) to the waste pile performed by foraging workers was recorded between 9:00 and 11:00 a.m., as was the number of autogrooming (i.e. self-grooming) and allogrooming (i.e. grooming of an individual by another of the same species) activities performed during the observation period.

The minor workers remain for much longer in the fungus garden and are involved in the tasks of mycelium manipulation (i.e. transferring hyphal fragments from one place to another within the fungus garden), mycelium hygienisation (grooming and removal of old fungus fragments) and larval transport. For better visualisation of these tasks, the fungus garden was placed in a transparent recipient, and the workers were observed with the aid of a magnifiying glass during task performance. There was no marking of workers; the order of the colony was random, and each colony was observed once per day for $30 \mathrm{~min}$; the number of times in which each activity was performed was recorded for the different colonies and treatments. 


\subsubsection{Queen-based reproductive assessment}

At the end of the experiment, 8 days from the offering of the ant baits, when the fipronil-treated colonies were virtually inactive, the queen of each colony was removed and dissected in saline solution for insects $\left(0.1 \mathrm{M}\right.$ of $\mathrm{NaCl}, 20 \mathrm{mM}$ of $\mathrm{KH}_{2} \mathrm{PO}_{4}, 20 \mathrm{mM}$ of $\left.\mathrm{Na}_{2} \mathrm{HP}_{4}\right)$. The reproductive tract of each queen was isolated, fixed and stored $\left(4^{\circ} \mathrm{C}\right)$ in Zamboni's fixative solution (paraformaldehyde + picric acid) for subsequent morphological inspection under a stereomicroscope (Stemi 2000; Zeiss, Göttingen, Germany) equipped with a digital camera (Canon Power A640; Canon, Lake Success, NY).

\subsection{Statistical analyses}

The mass of bait granules collected by the foraging workers with or without fipronil, as well as the total mass of harvest leaves and dead workers, was compared by Student's $t$-test $(P<0.05)$ (Systat v.13; Systat, San Jose, CA). All of the other response variables recorded (i.e. number of workers involved in the different activities recorded) followed an approximate normal distribution, and least-squares regression analyses were performed over time after bait introduction, using the curve-fitting procedure of TableCurve 2D v.5.01 (Systat). The regression models to describe the response (i.e. dependent) variables were selected on the basis of parsimony, high $F$-values and steep increases in $R^{2}$ with model complexity. The regression responses for treated and untreated colonies were distinguished on the basis of the different models obtained, their distinct equation parameters and also the non-overlapping means and respective standard errors of the observed data points of each regression curve.

\section{RESULTS}

\subsection{Colony-level effect of fipronil}

The mass of bait granules collected by the ant colonies did not differ between treatments, with fipronil not interfering with bait pick-up by foraging workers $\left(t_{8}=1.24, P=0.25\right)$. The foraging ants collected $1.09 \pm 0.25 \mathrm{~g}$ of placebo baits and $1.80 \pm 0.51 \mathrm{~g}$ of fipronil-containing baits in $24 \mathrm{~h}$. In contrast, leaf harvesting by the ant colonies greatly differed between treatments, with significantly more leaves cut on the placebo-provided colonies $(14.69 \pm 3.41 \mathrm{~g})$ than in the fipronil-provided colonies $(3.85 \pm 0.86 \mathrm{~g})\left(t_{8}=3.08, P=0.01\right)$. The colonies provided with fipronil-containing baits exhibited significant reduction $24 \mathrm{~h}$ after the bait was offered, and with further steady decline thereafter, when compared with the colonies provided with placebo baits (i.e. not containing fipronil) $\left(F_{1,27}=8.68, P=0.006\right)$, which remained relatively constant throughout the experiment $(2.60 \pm 0.09 \mathrm{~g}$; $P>0.05$ ) (Fig. 1a). The mass of dead ants observed in the colony waste piles was also distinct between treatments (placebo: $0.15 \pm 0.05 \mathrm{~g}$ dead ants colony ${ }^{-1}$; fipronil: $4.69 \pm 0.14 \mathrm{~g}$ dead ants colony $\left.^{-1} ; t_{8}=3.99, P=0.004\right)$, particularly $24 \mathrm{~h}$ after bait provision (Fig. 1b). While the placebo-baited colonies exhibited a low number of dead ants in the colony waste piles, which did not vary with time $(0.26 \pm 0.07 \mathrm{~g} ; P>0.05)$, the amount of dead ants was very high at the start of the assessments for the fipronil-baited colonies and declined thereafter until it matched that of the control 8 days after the bait provision $\left(F_{1,30}=3.03, P=0.01\right)$ (Fig. $1 \mathrm{~b}$ ). Although ants from different castes were observed in the waste piles, the amount of dead minor workers largely dominated in the fipronil-baited colonies, particularly at the onset of the bait provision. All of the fipronil-baited colonies died after 8 days of bait provision, unlike the placebo-baited colonies. (a) Daily harvest of freshly cut leaves

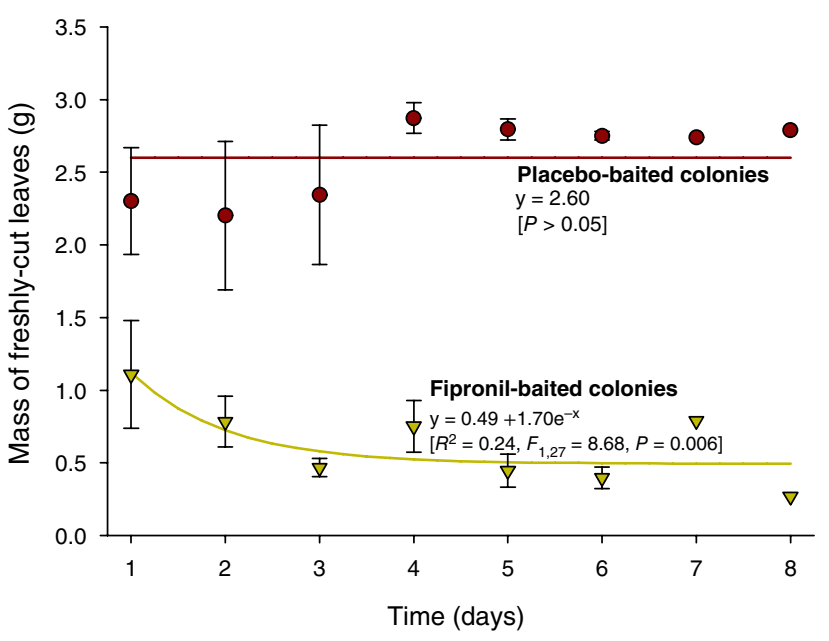

(b) Mass of dead ants removed daily from nest

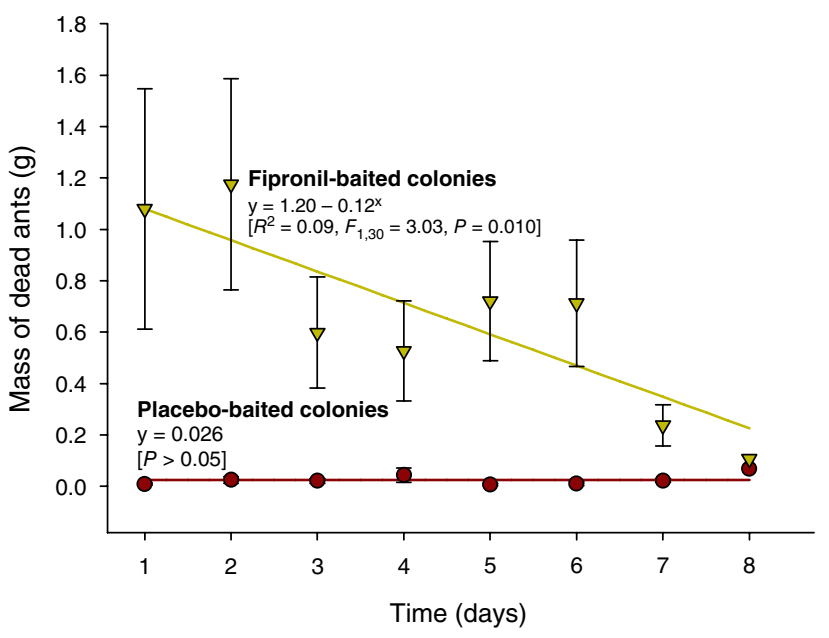

Figure 1. Mass of freshly cut leaves harvested (a) and mass of dead ants (b) in colonies of the leaf-cutting ant species Acromyrmex subterraneus subterraneus provided either with fipronil or with placebo bait granules. Each symbol represents the mean of five biological replicates (i.e. colonies), and the vertical bars represent the associated standard errors obtained from daily 30 min observation for eight consecutive days.

\subsection{Worker-level effect of fipronil}

The number of waste removal activities performed by foraging workers in the colony declined with time in both treatments. However, such decline was steeper for the fipronil-baited colonies, nearly stopping after 4 days of the bait provision $\left(F_{1,43}=25.50\right.$, $P<0.001$ ); in the placebo-baited colonies such activity was maintained until the end of the experiment (i.e. 8 days after bait provision) $\left(F_{1,34}=7.17, P=0.01\right)$ (Fig. 2). The number of autoand allogrooming interactions among foraging workers did not vary with time among the placebo-baited colonies, but quickly declined with time in the fipronil-baited colonies (Fig. 3). At $24 \mathrm{~h}$ after bait provision, the autogrooming was already significantly less frequent in the fipronil-baited colonies $\left(F_{1,34}=59.18\right.$, $P<0.001)$ than in the placebo-baited colonies $(19.27 \pm 0.56$ autogroomings; $P>0.05$ ) (Fig. 3a). The allogrooming interactions exhibited a distinct diminishing trend, with small differences between treatments $24 \mathrm{~h}$ after bait provision and rapid increase 


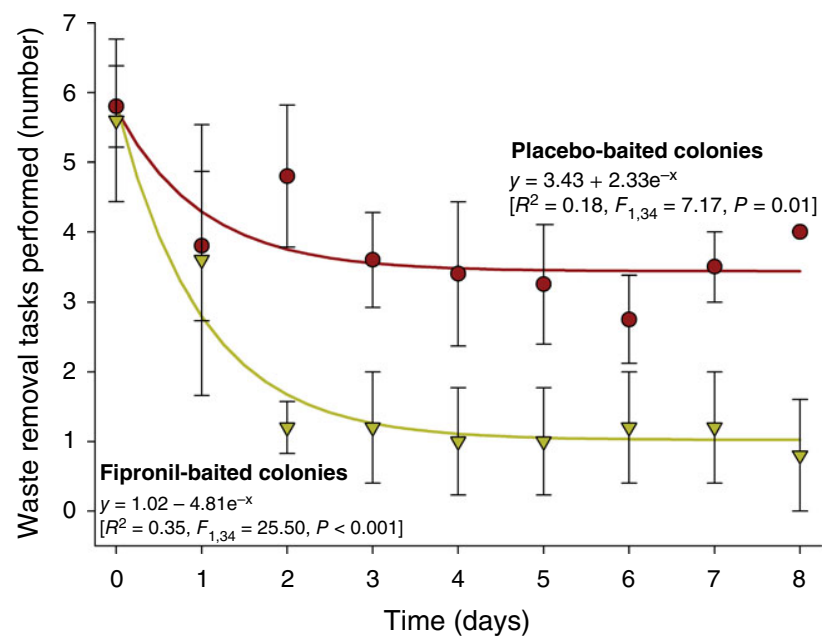

Figure 2. Number of waste removal tasks performed by foraging workers from colonies of the leaf-cutting ant species Acromyrmex subterraneus subterraneus provided either with fipronil or with placebo bait granules. Each symbol represents the mean of five biological replicates (i.e. colonies), and the vertical bars represent the associated standard errors obtained from daily $30 \mathrm{~min}$ observation for eight consecutive days.

thereafter until allogrooming interactions completely stopped 3 days after fipronil bait offering $\left(F_{1,34}=79.98, P<0.001\right)$ (Fig. 3b).

The common behavioural activities of minor ants in the fungus garden are the manipulation of mycelium hyphae and the mycelium hygienisation (grooming and removal of old fungus fragments), along with larval transport. The number of mycelium manipulation tasks performed by minor workers varied with time, but remained higher in placebo-baited colonies throughout the experiment $(3.78 \pm 0.50$ mycelium manipulation tasks performed; $P>0.05)$, while such activity decreased $24 \mathrm{~h}$ after fipronil bait access to negligible levels after 4 days $\left(F_{1,34}=40.55\right.$, $P<0.001$ ) (Fig. 4a). Mycelium hygienisation also differed between treatments. The placebo-baited colonies maintained the same level of activity through time $(4.11 \pm 0.44$ mycelium hygienisation tasks performed; $P>0.05$ ), while mycelium hygienisation in the fipronil-baited colonies declined, with grooming stopping almost completely 6 and 7 days after baiting $\left(F_{1,34}=40.55, P<0.001\right)$ (Fig. 4b). Larval transport also declined with time, but was significantly more compromised in fipronil-baited colonies, which exhibited only negligible activity as early as 4 days after the bait supply $\left(F_{1,34}=42.72, P<0.001\right)$ (Fig. 5).

\subsection{Queen-level effect of fipronil}

The reproductive tract of the queens was inspected under a stereomicroscope to assess reproductive impairment. All of the inspected queens, from either the placebo- or the fipronil-baited colonies, exhibited healthy reproductive tracts without any apparent differences (supporting information Fig. S1). The ovaries were not atrophied, and the eggs were visible in the oviducts with the production of apparently healthy eggs and young larvae.

\section{DISCUSSION}

Fipronil is one of the few successful insecticides in use in toxic attractive baits for managing leaf-cutting ants, particularly in eucalypt forests in Neotropical America. ${ }^{4,9}$ The underlying mechanism of colony suppression was unknown for fipronil. Here we attempted to shed light on the mechanism of how fipronil (a) Autogrooming

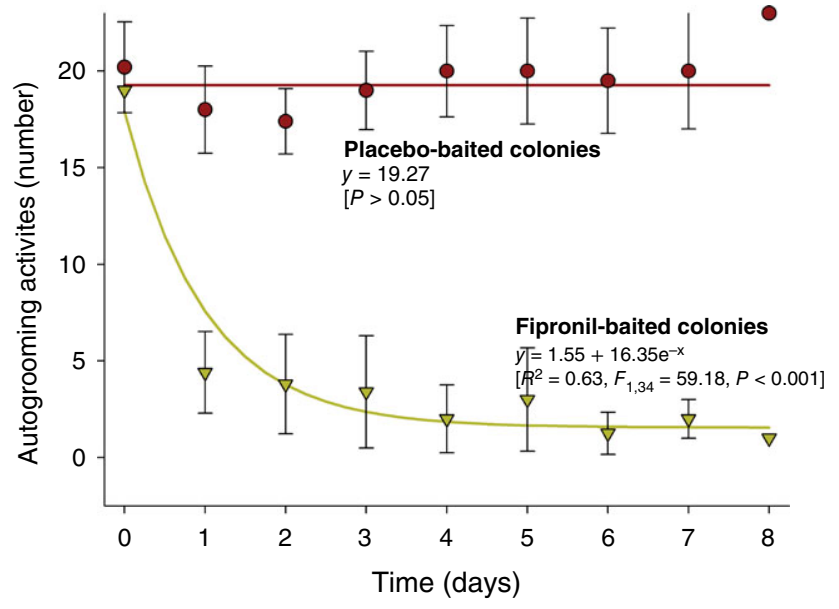

(b) Autogrooming

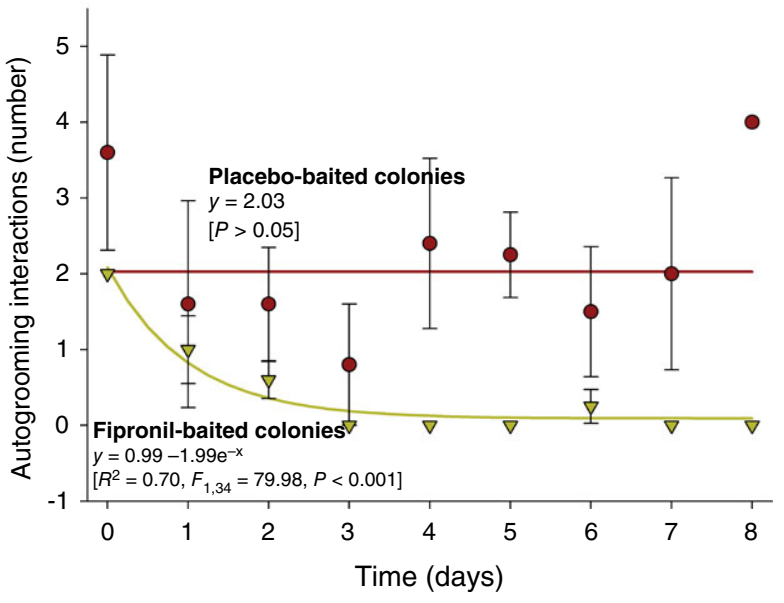

Figure 3. Number of autogrooming (a) and allogrooming (b) interactions performed by foraging workers in colonies of the leaf-cutting ant species Acromyrmex subterraneus subterraneus provided either with fipronil or with placebo bait granules. Each symbol represents the mean of five biological replicates (i.e. colonies), and the vertical bars represent the associated standard errors obtained from daily $30 \mathrm{~min}$ observation for eight consecutive days.

achieves ant colony suppression, which could be by means of (i) directly impairing the ant queen reproductive output and/or directly compromising either (ii) the fungus garden or (iii) the minor workers handling the fungus garden and the queen progeny. ${ }^{4,17,18}$

We hypothesised that the direct effect of fipronil on minor workers was likely more important than its direct effects on the ant queen and fungus garden without directly compromising the foraging workers. This expectation was based on the lack of reported fungicide activity of fipronil and its neurotoxic rather than sterilant effect on insects, besides the need for the toxic baits to be picked up by the foraging workers and introduced into the nest. 4,17,23,25,26 Indeed, the results obtained provided support for our hypothesis of a prevailing minor-worker-targeted activity compromising the care of the fungus garden and thus ultimately allowing it to be overrun with Escovopsis, an opportunistic parasitic fungus in ant-fungus symbiosis. 
(a) Mycelium manipulating

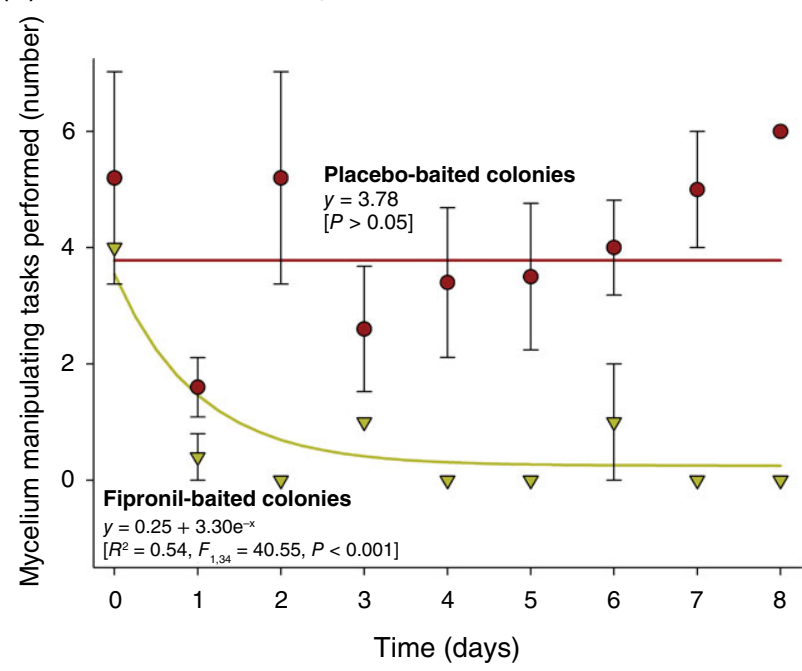

(b) Mycelium grooming

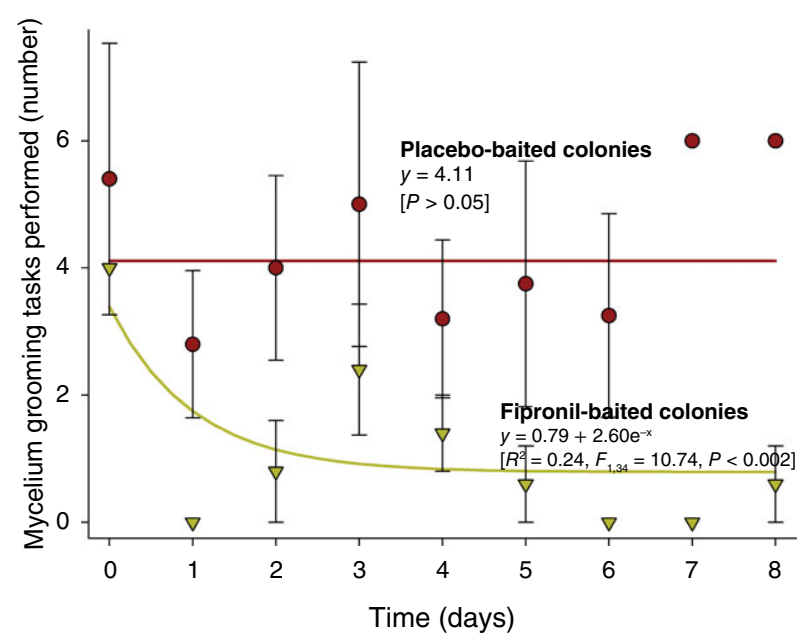

Figure 4. Number of mycelium hypha manipulation tasks (a) and mycelium hygienisation (mycelium grooming) tasks (b) performed by minor workers in the fungus garden of colonies of the leaf-cutting ant species Acromyrmex subterraneus subterraneus provided either with fipronil or with placebo bait granules. Each symbol represents the mean of five biological replicates (i.e. colonies), and the vertical bars represent the associated standard errors obtained from daily $30 \mathrm{~min}$ observation for eight consecutive days.

Fipronil did not interfere with bait pick-up by the foraging workers, which were able to introduce the fipronil bait granules into the nest at the same rate as the placebo bait granules. Therefore, no repellence or direct short-term acute mortality was detected in the foraging ants, which were well accepted into the colony, a pivotal bait trait for its success in suppressing colonies of leaf-cutting ants such as $A$. s. subterraneus. ${ }^{9,13}$ The fipronil-baited ant colonies were quickly suppressed within 3-4 days, again reinforcing the high efficacy of fipronil baits for leaf-cutting ants.

The queens of the leaf-cutting ants baited with fipronil did not exhibit any signs of reproductive impairment as their reproductive tract remained healthy, with produced eggs visible within the ovarioles. The marks of egg release were also visible, as was a still full spermatheca. Another clue to queen fertility was the presence of new brood until the suppression of the fungus garden.

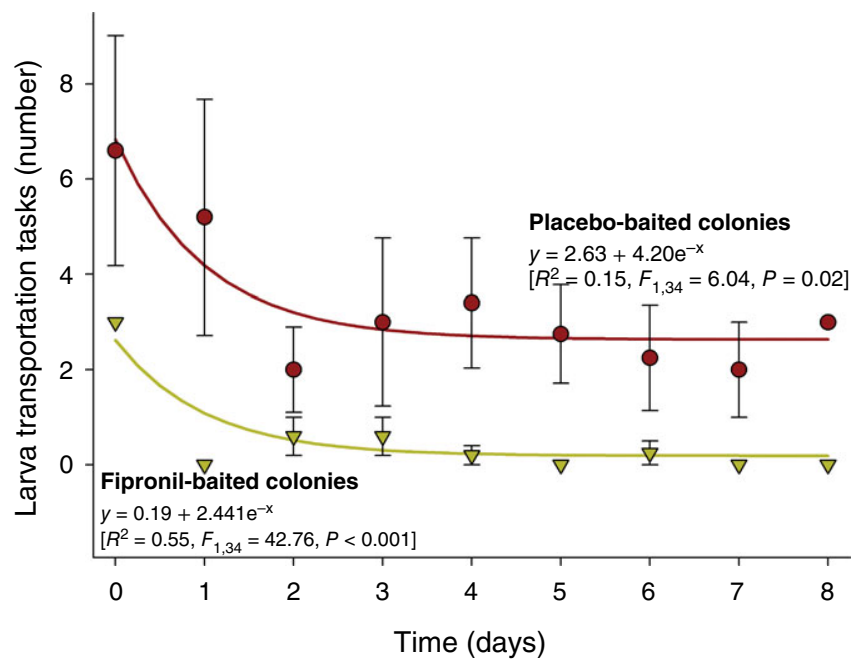

Figure 5. Larva transportation activity performed by minor workers within colonies of the leaf-cutting ant species Acromyrmex subterraneus subterraneus provided either with fipronil or with placebo bait granules. Each symbol represents the mean of five biological replicates (i.e. colonies), and the vertical bars represent the associated standard errors obtained from daily 30 min observation for eight consecutive days.

Therefore, this insecticide does not seem directly to impair queen reproduction, unlike the sterilant effect caused by abamectin in queens of leaf-cutting ants. ${ }^{18,19}$ Such an effect of abamectin led to the suppression of colonies of the same leaf-cutting ant species in our experiment, $A$. s. subterraneus, but the said suppression took a relatively long time to occur (over 9 weeks), thus limiting the potential use of this compound in toxic baits., 4,9,18,19

Fungicidal activity has never been associated with fipronil, thus the perception that it directly affects the fungus garden of leaf-cutting ants is unlikely. ${ }^{23-26}$ Curiously, the fipronil-baited colonies exhibited a quick debilitation and decline of the fungus garden, which became heavily contaminated with Escovopsis, a specialised and occasionally virulent fungus able to attack and eliminate the ant fungus. ${ }^{31,32}$ Thus, as fipronil did not directly affect either fungus (i.e. ant garden fungus or Escovopsis), no fungicidal activity by fipronil was apparent. However, the insecticide did favour Escovopsis contamination and eventual suppression of the fungus garden. This is explained by the insecticidal activity of the bait over the minor workers that handle the fungus garden, which differ in size and behaviour from the foraging workers, which may account for their differences in susceptibility to fipronil. Minor workers, for instance, remain longer in contact with the baits, allowing higher levels of exposure to fipronil than foraging workers.

While both forager and minor workers were affected by fipronil, the insecticide exhibited mild effects on the foragers, which did not hinder the harvesting of freshly cut leaves. However, fipronil affected both auto- and allogrooming, and interfered with minor worker activities within the nest, noticeably waste removal. The higher mortality of minor workers likely contributed to the changes in their behaviour recorded in our study, but as minor workers from colonies of similar density from different treatments also exhibited altered behaviour, fipronil was probably the main mediator of such changes. Regardless, nest hygiene and protection were compromised owing to eventual failure in recognising and removing fipronil-intoxicated ants and allowing contamination of the fungus garden. 
Fast $(<24 \mathrm{~h})$ and extensive mortality of minor workers took place under fipronil exposure via attractive baits, which was observed in our assessments and reported here. Mortality resembled what has been reported for the organochlorine dodecachlor, the use of which in insecticidal baits against leaf-cutting ants was common until its eventual prohibition in the early 1990s. ${ }^{13,15,16}$ In our study we were able further to observe that the surviving (minor) workers were unable to perform their tasks within the nest, with fipronil affecting their handling of the progeny and of the fungus garden, allowing the contamination of the latter by the Escovopsis fungus. This supplemented the reported behavioural effects observed in the foraging workers, which further facilitated the impact of fipronil in the colony, leading to its quick suppression.

The fipronil activity that primarily targeted minor workers of the leaf-cutting ants, probably aided by the impairment of protective and hygienic behaviours, led to a fast decay of the fungus garden and likely progeny mishandling. This compromised colony sustainability and resulted in colony demise in 4-8 days. Such effects are therefore worthy targets in developing alternative insecticidal compounds and other control tactics for the leaf-cutting ant. The association of neurotoxic insecticide and pathogen also seems promising, as recently suggested. ${ }^{4,33,34}$ This is plausible because the former can impair the ants' naturally protective behaviour against pathogen contamination, which is the alleged cause of the little success so far obtained with entomopathogen use against leaf-cutting ants, despite the high laboratory efficacy of the tactic. 4,35,36 Thus, the findings reported here suggest alternative venues in pursuing management of leaf-cutting ants in forest plantations that are consistent with current demands of certification agencies and product marketability.

\section{ACKNOWLEDGEMENTS}

The financial support provided by the National Council of Scientific and Technological Development (CNPq), the CAPES Foundation (Brazilian Ministry of Education) and the Minas Gerais State Foundation of Research Aid (FAPEMIG) is greatly appreciated.

\section{SUPPORTING INFORMATION}

Supporting information may be found in the online version of this article.

\section{REFERENCES}

1 Fowler HG, Pagani MI, Silva AO, Forti LC, Pereira-da-Silva V and Vasconcelos $\mathrm{HL}$, A pest is a pest? The dilemma of Neotropical leaf-cutting ants: keystone taxa of natural ecosystems. Environ Manag 13:671-675 (1989).

2 Wirth R, Herx H, Ryel RJ, Beyschlag W and Hölldobler B, Herbivory of Leaf-Cutting Ants. Springer-Verlag, Berlin, Germany (2003).

3 Della Lucia TMC and de Souza DJ, Importância e história de vida das formigas-cortadeiras, in Formigas-Cortadeiras - da Biologia ao Manejo, Vol. 1, ed. by Della Lucia TMC. Editora UFV, Viçosa, MG, Brazil, pp. 13-26 (2011).

4 Della Lucia TMC, Gandra LC and Guedes RNC, Managing leaf-cutting ants: peculiarities, trends and challenges. Pest Manag Sci 70:14-23 (2014).

5 Hölldobler B and Wilson EO, The Ants. Harvard University Press, Cambridge, MS (1990).

6 Montoya-Lerma J, Giraldo-Echeverri C, Armbrecht I, Farji-Brener A and Calle $Z$, Leaf-cutting ants revisited: towards rational management and control. Int J Pest Manag 53:225-247 (2012).

7 Mora AL and Garcia CH, Eucalypt Cultivation in Brazil. SBS, São Paulo, Brazil (2000).
8 Anuário Estatístico ABRAF 2013, ABRAF, Brasília, Brazil (2013).

9 Oliveira MA, Araújo MS, Marinho CGS, Ribeiro MMR and Della Lucia TMC, Manejo de formigas-cortadeiras, in Formigas-Cortadeiras - da Biologia ao Manejo, Vol. 1, ed. by Della Lucia TMC. Editora UFV, Viçosa, MG, Brazil, pp. 400-419 (2011).

10 Approved derogations for use of 'highly harzadous' pesticides. FSC-GUI-30-001 Version 1-O EN, Forest Stewardship Council, Bonn, Germany (2010).

11 Isenring R and Neumeister L, Recommendations Regarding Derogations to Use Alpha-Cypermethrin, Deltamethrin, Fenitrothion, Fipronil and Sulfluramid in FSC Certified Forests in Brazil. Forest Stewardship Council, Bonn, Germany (2010).

12 Souza LF, As formigas cortadeiras e o seu combate por meio de iscas granuladas. Bol Campo 18:5-6 (1962).

13 Della Lucia TMC and Vilela EF, Métodos atuais de controle e perspectivas, in As Formigas Cortadeiras, ed. by Della Lucia TMC. Folha de Viçosa, Viçosa, MG, Brazil, pp. 163-190 (1993).

14 Boareto MAC and Forti LC, Perspectiva no controle de formigas-cortadeiras. Ser Tecn IPEF 11:31-46 (1997).

15 Gallo D, Nakano O, Silveira Neto S, Carvalho RPL, Batista GC, Berti Filho E et al., Manual de Entomologia Agrícola, 2nd edition. Ceres, São Paulo, Brazil (1988).

16 Della Lucia TMC and Araújo MS, Formigas-cortadeiras: atualidades no combate, in Manejo Integrado - Doenças, Pragas e Plantas Daninhas, ed. by Zambolim L. Editora UFV, Viçosa, MG, Brazil, pp. 245-273 (2000).

17 Guedes RNC, Smagghe G, Stark JD and Desneux N, Pesticide-induced stress in arthropod pests for optimized integrated pest management programs. Annu Rev Entomol DOI: 10.1146/annurev-ent-010715-023646 (2016).

18 Antunes EC, Guedes RNC, Della Lucia TMC and Serrão JE, Sublethal effects of abamectin suppressing colonies of the leaf-cutting ant Acromyrmex subterraneus subterraneus. Pest Manag Sci 56:1059-1064 (2000).

19 Antunes EC, Della Lucia TMC, Guedes RNC and Serrão JE, Abamectin-driven alterations on queen ovaries of the leaf-cutting ant Acromyrmex subterraneus subterraneus (Hymenoptera: Formicidae). Sociobiology 45:163-172 (2005).

20 Marinho CGS, Della Lucia TMC, Guedes RNC, Ribeiro MMR and Lima ER, $\beta$-Eudesmol induced aggression in the leaf-cutting ant Atta sexdens rubropilosa. Entomol Exp Applic 117:89-93 (2005).

21 Marinho CGS, Della Lucia TMC, Ribeiro MMR, Magalhães STV, Guedes RNC and Jham GN, Interference of $\beta$-eudesmol in nestmate recognition in Atta sexdens rubropilosa (Hymenoptera: Formicidae). Bull Entomol Res 98:467-473 (2008).

22 Marinho CGS, Ribeiro MMR, Della Lucia TMC and Guedes RNC, Aggressive response of pest ant species to $\beta$-eudesmol (Hymenoptera: Formicidae). Sociobiology 47:445-454 (2006).

23 Hainzl D, Cole LM and Casida JE, Mechanisms for selective toxicity of fipronil insecticide and its sulfone metabolite and desulfinyl photoproduct. Chem Res Toxicol 11:1529-1535 (1998).

24 Tingle CC, Rother JA, Dewhurst CF, Lauer S and King WJ, Fipronil: environmental fate, ecotoxicology, and human health concerns. Rev Environ Contam Toxicol 176:1 - 66 (2003).

25 Salgado VL, Schmatterer S and Holmes KA, Ligand-gated chloride channel antagonists (fiproles), in Modern Crop Protection Compounds, vol. 3, ed. by Krämer W, Schirmer U, Jeschke $P$ and Witschel M. Wiley-VCH, Weinheim, Germany, pp. 1283-1326 (2012).

26 Casida JE and Durkin KA, Neuractive insecticides: targets, selectivity, resistance, and secondary effects. Annu Rev Entomol 58:99-117 (2013).

27 Pisa LW, Amaral-Rogers V, Belzunces LP, Bonmatin JM, Downs CA, Goulson D et al., Effects of neonicotinoids and fipronil on non-target invertebrates. Environ Sci Pollut Res 22:68-102 (2015).

28 Delabie JHC, Alves HSR, Reuss-Strenzel GM, do Carmo AFR and do Nascimento IC, Distribuição das formigas-cortadeiras dos gêneros Acromyrmex e Atta no Novo Mundo, in Formigas-Cortadeiras - da Biologia ao Manejo, Vol. 1, ed. by Della Lucia TMC. Editora UFV, Viçosa, MG, Brazil, pp. 80-101 (2011).

29 Della Lucia TMC, Vilela EF, Anjos N and Moreira DDO, Criação de formigas-cortadeiras em laboratório, in As Formigas Cortadeiras, ed. by Della Lucia TMC. Folha de Viçosa, Viçosa, MG, Brazil, pp. 151-162 (1993).

30 Antunes EC and Della Lucia TMC, Consumo foliar em Eucalyptus urophylla por Acromyrmex laticeps nigrosetosus Forel (Hymenoptera: Formicidae). Ciênc. Agrotec 23:208-221 (1999). 
31 Currie CR, Muller UG and Malloch D, The agricultural pathology of ant fungus gardens. Proc Natl Acad Sci USA 96:7998-8002 (1999).

32 Currie CR, Bot ANM and Boomsma JJ, Experimental evidence of a tripartite mutualism: bacteria protect ant fungus gardens from specialized parasites. Oikos 101:91-103 (2003).

33 Santos AV, Oliveira BL and Samuels RI, Selection of entomopathogenic fungi for use in combination with sub-lethal doses of imidacloprid: perspectives for the control of the leaf-cutting ant Atta sexdens rubropilosa Forel (Hymenoptera: Formicidae). Mycopathologia 163:233-240 (2007).
34 Galvanho JP, Carreira MP, Moreira DDO, Erthal M, Jr, Silva CP and Samuels Rl, Imidacloprid inhibits behavioral defenses of the leaf-cutting ant Acromyrmex subterraneus subterraneus (Hymenoptera: Formicidae). J Insect Behav 26:1-13 (2013).

35 Hughes DP, Evans HC, Hywel-Jones N, Boomsma JJ and Armitage $\mathrm{SAO}$, Novel fungal disease in complex leaf-cutting ant societies. Ecol Entomol 34:214-220 (2009).

36 Diehl-Fleig E, da Silva ME, Specht A and Valim-Labres ME, Efficiency of Beauveria bassiana for Acromyrmex spp. control (Hymenoptera: Formicidae). Ann Soc Entomol Brasil 22:233-240 (1993). 